Article

\title{
Improved Dynamic Voltage Regulation in a Droop Controlled DC Nanogrid Employing Independently Controlled Battery and Supercapacitor Units
}

\author{
Ahmad M. A. Malkawi * and Luiz A. C. Lopes \\ Department of Electrical and Computer Engineering, Concordia University, Montreal, QC H4G 2M1, Canada; \\ lalopes@ece.concordia.ca \\ * Correspondence: ah_malk@encs.concordia.ca; Tel.: +1-514-586-9650
}

Received: 23 July 2018; Accepted: 29 August 2018; Published: 1 September 2018

Featured Application: Control the hybrid energy storage systems in microgrid and nanogrid.

\begin{abstract}
DC bus voltage signaling (DBS) and droop control are frequently employed in DC nano and microgrids with distributed energy resources (DERs) operating in a decentralized way. This approach is effective in enforcing the desired contributions of power sources and energy storage systems (ESSs) in steady-state conditions. The use of supercapacitors (SCs) along with batteries in a hybrid energy storage system (HESS) can mitigate the impact of high and fast current variations on the losses and lifetime of the battery units. However, by controlling the HESS as a single unit, one forfeits the potential contribution of the SC and its high power capabilities to dynamically improve voltage regulation in a DC nanogrid. This paper discusses an approach where the SC interface is controlled independently from the battery interface, with a small droop factor and a high pass filter (HPF), to produce high and short current pulses and smooth DC bus voltage variations due to sudden power imbalances in the DC nanogrid. Experimental results are presented to show that, unlike in a conventional HESS, the SC unit can be used to improve the dynamic voltage regulation of the DC nanogrid and, indirectly, mitigate the high and fast current variations in the battery.
\end{abstract}

Keywords: DC nanogrid; droop control; DC bus signaling; supercapacitor; hybrid energy storage system; power quality; smooth transition

\section{Introduction}

Due to environmental issues and the shortage of fossil fuel, the participation of renewable energy sources (RESs) in the power system is expected and desired to increase. Since these are suitable for decentralized deployment, the power distribution system of the future could be designed and operated considering a hierarchical configuration consisting of micro and nanogrids. In fact, homes and neighborhoods can become net-zero energy nano and microgrids [1]. That is to say that the total amount of energy used by a home and/or neighborhood, on an annual basis, is nearly equal to the amount of energy produced by RESs [2]. Assuming that micro and nanogrids are expected to be able to operate autonomously, the most significant challenge is power availability, because the power generated by the RESs is variable and depends on environmental conditions. In such a case, the nano and microgrids should be supported by properly sized and controlled energy storage systems (ESSs). Besides, the system should be able to balance supply and demand obtaining high levels of power quality in both steady-state and transient conditions.

The most commonly used energy storage elements in ESSs are batteries, due to their high energy densities. On the other hand, in general, batteries present relatively low power densities, making 
it difficult for them to compensate for large and sudden power unbalances. This condition can lead to increased power losses and high operating temperatures, which can significantly decrease the lifetime of the battery. Keeping the battery operating as close as possible to the ideal conditions respecting the recommended state-of-charge $(\mathrm{SoC})$ ranges, charging and discharging rates, temperature and cell-charge equalization is very important according to [3,4]. Hybrid energy storage systems (HESSs), with battery and supercapacitor (SC), have been proposed to strike a balance between the complementary characteristics of these two energy storage means $[5,6]$. The SC can compensate transient power fluctuations while the battery supplies the average and slow varying power demand [5-7].

The literature reports several approaches for controlling the power sharing between the battery and the SC in applications with HESSs. A two level electrical storage system is presented in [8] to deal with the power fluctuation of RESs. The stress on the battery can be mitigated by a control algorithm that extracts the maximum power from the RESs and uses the SC to deal with the high frequency components of the RES' power fluctuation [9]. A model predictive control system for a HESS is proposed in [10] where a model of the battery and SC is used to generate the gating signals of the DC-DC converters (interfaces) with the high frequency power supplied by the SC. A supervisory energy management strategy (EMS) based on neural networks, which is rather complicated, is proposed in [11]. It has been shown in [12] that a dynamic EMS in a RES integrated with a HESS can provide effective active DC link voltage regulation and reduced current stress on the battery [12]. All these algorithms are based on centralized control employing a communication link between the distributed energy resources (DERs). However, if communication fails, the system is disabled. Thus, centralized control schemes tend to present lower reliability [13-15]. Since battery and SC in a HESS are usually co-located and the main task of the $\mathrm{SC}$ is to prevent the fast varying current components from circulating through the battery, a simple scheme with frequency component separation, based on a low pass filter (LPF) or a high pass filter (HPF) is usually employed [16]. The high frequency and fast varying current components to be supplied by the HESS are processed by the high power density SC, while the average and slow varying components are dealt with by the battery. One issue with this approach is that it tends to forfeit the potential contribution of the SC and its high power capabilities to dynamically improve power quality in a DC nanogrid.

DC bus signaling (DBS) and droop control are frequently employed in DC nano and microgrids with various DERs operating in a decentralized way [12]. They are based on locally measured variables, such as DC bus voltage, and provide an effective means for setting power sharing among parallel units in steady-state conditions. This is achieved by defining two parameters: the droop $(\Delta V / \Delta I)$ slope (factor) and the threshold (no-load) voltage. The first is usually defined based on the power ratings of the DERs and remains constant. The larger units have smaller droop slopes to take larger shares of the power/current required for balancing supply and demand, mitigating DC bus voltage variations $(\Delta \mathrm{V})$. The threshold voltage is used for energy management and can be updated by a supervisory controller employing low bandwidth communication, but is not essential for system operation. Disregarding the latter, for high reliability, and assuming that he SC and battery are not co-located, the SC unit should present a droop factor lower than that of the battery's to be able to contribute more to dynamic voltage regulation. However, additional means are required to accommodate its low energy capacity constraint. For that, a HPF with a properly selected cut-off frequency is proposed in this paper. Simulation and experimental results are presented to show that this approach can provide an improvement in the dynamic regulation of the DC nanogrid voltage as well as mitigate the fast current components in the battery unit.

\section{Power Control and Current Sharing of DERs}

The DC nanogrid considered in this paper consists of a RES, battery and SC storage units and a variable load as shown in Figure 1. The RES employs a uni-directional boost converter, while the storage units require a bi-directional one, typically a class C DC-DC converter. The battery and SC can be controlled as a single HESS, in which case they should be co-located, or independently 
what is suitable for distributed energy storage units, as proposed in this paper. The single-bus DC nanogrid is controlled in a decentralized way with a hierarchical structure based on DBS and droop control. However, no communication means for energy management is considered in this paper. DBS uses the DC bus voltage itself as the communication link to coordinate the operation of DERs in a decentralized way. With droop control, the current (power) injected by each DER in the nanogrid depends on its threshold voltage $\left(V_{N L}\right)$, where the injected current is zero, and its droop slope (factor) $R_{d}$ as shown in Equation (1). The latter determines how the injected current varies as a function of grid voltage variations.

$$
I_{D C}=\left(V_{N L}-V_{D C}\right) \frac{1}{R_{d}},
$$

where;

$$
R_{d}=\frac{\Delta V_{D C}}{\Delta I_{D C}}
$$

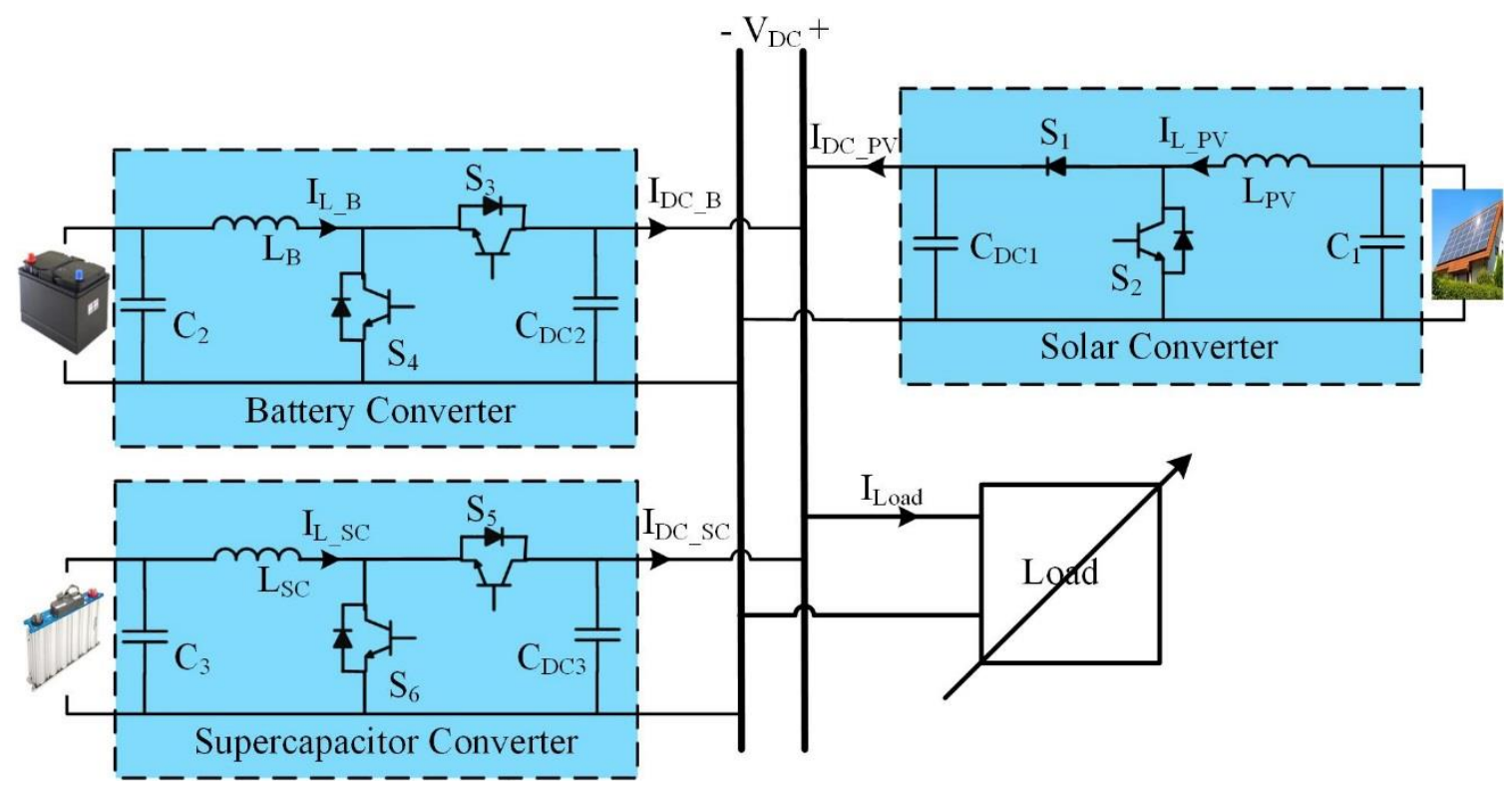

Figure 1. Autonomous DC nanogrid considered in this study.

In the hierarchical structure, DBS is the primary control level of the nanogrid. The DC nanogrid considered in this paper has a nominal voltage of $1 \mathrm{pu}$. It was conceived to operate with a voltage regulation of about $\pm 5 \%$, giving an operating DC bus voltage between $0.95 \mathrm{pu}$ and $1.05 \mathrm{pu}$. In the case of the RESs, the threshold voltage is often taken as $V_{N L_{-} P V}=1.05 \mathrm{pu}$, higher than the threshold voltage of the energy storage unit or HESS, $V_{N L} S T=1 \mathrm{pu}$. In the concept of DBS, it gives the RESs, if available and producing power, the highest priority to feed the loads. As shown in Figure 2, by the blue curve, the solar converter operates in three regions: droop, constant power, and constant current-limited with unidirectional power flow. When the DC bus voltage is between $1.05 \mathrm{pu}$ and $1.025 \mathrm{pu}$, the solar converter operates with droop factor $R_{d P V}$. Therefore, the solar generates the maximum power at $V_{D C}=1.025 \mathrm{pu}$ and starts to operate at maximum power point tracking (MPPT) with the rated solar irradiance. When the PV has a maximum power less than the rated power, due to a lower solar irradiance, the solar converter should start to operate at MPPT before the DC bus voltage drops below $1.025 \mathrm{pu}$, what can be done by "reprogramming" the V-I curve of the solar converter, as shown in the dashed line in Figure 2. For instance, the solar converter should start to operate at MPPT with a DC bus voltage of 1.029 pu with a maximum power of $90 \%$ from the rated power. When the DC bus voltage drops below $0.95 \mathrm{pu}$ for rated solar irradiance, the solar converter starts to operate in the constant current-limited mode. 


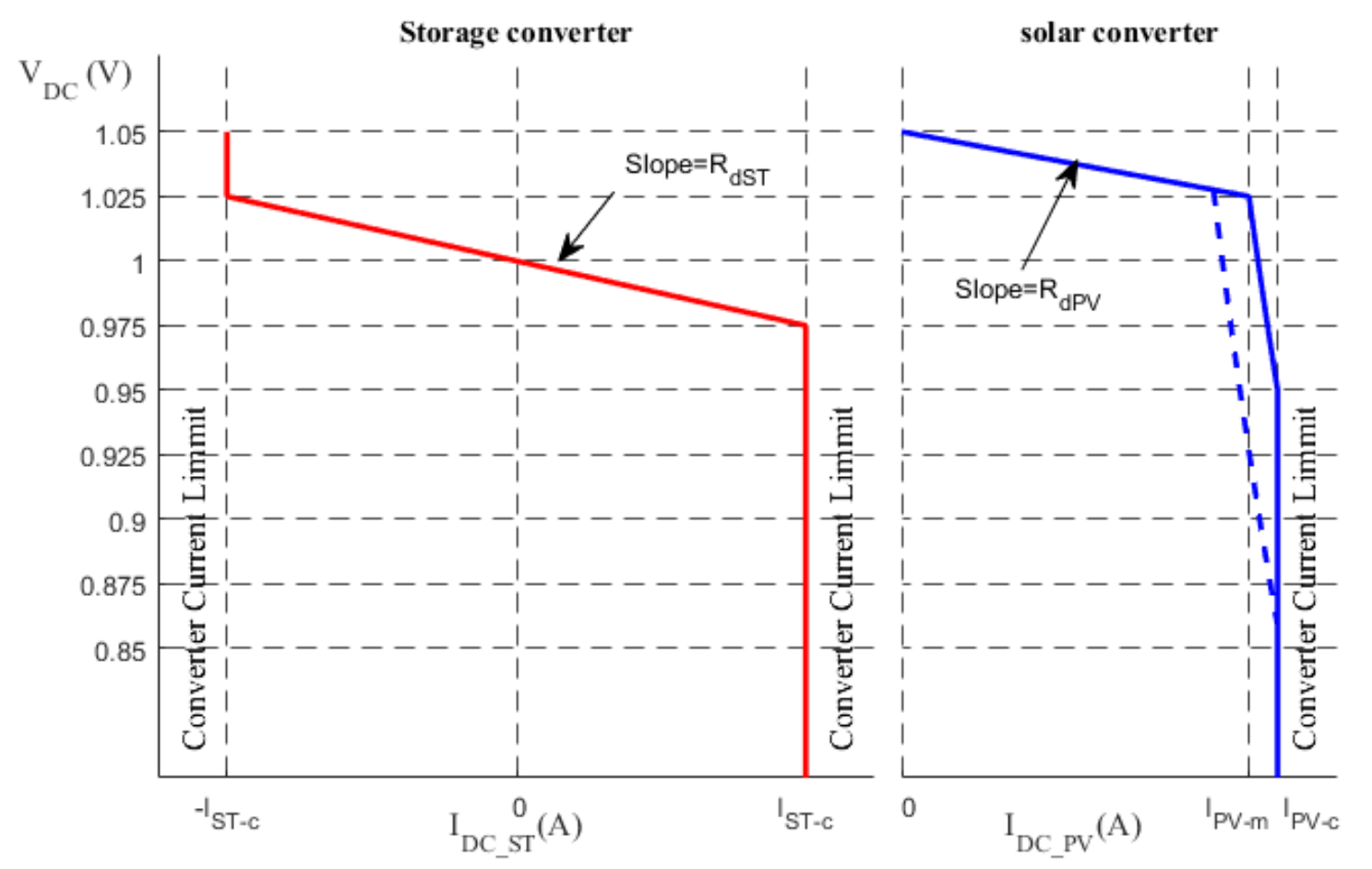

Figure 2. V-I curves of the storage and solar (renewable energy source (RES)) converters.

The V-I curve of the energy storage unit or HESS is the red curve in Figure 2, presenting only droop and current limiting modes. When the DC bus voltage is between $1.025 \mathrm{pu}$ and $0.975 \mathrm{pu}$, the storage converter operates with droop factor $R_{d S T}$. Otherwise, it operates with a constant (rated) negative current at a DC bus voltage higher than $1.025 \mathrm{pu}$ and constant positive current at a DC bus voltage lower than $0.975 \mathrm{pu}$. The storage unit charges when the $\mathrm{DC}$ bus voltage is higher than $1 \mathrm{pu}$, as indicated by a "negative injected current." Conversely, it discharges at DC bus voltages less than $1 \mathrm{pu}$.

\section{Conventional and Proposed Control Schemes of the Battery-SC HESS}

In the conventional approach, shown in Figure 3, the battery and SC are co-located and controlled as a HESS to realize a given V-I curve or droop characteristic. The supercapacitor operates in parallel with the battery to provide short bursts of power that eliminate the high-frequency components in the transient battery current response, so that the battery current has a smooth transition. In a DC nanogrid with droop control, the DC bus voltage is sensed, and an outer voltage loop with a proportional (P) controller, which corresponds to the droop action, produces a reference current to be realized by the battery and the SC converters. The slow and fast changing components of the reference current are split, by means of either a high-pass filter (HPF) or a low-pass filter (LPF). The slow ones are used as a reference for the inner battery current control loop, while the fast ones are used for the inner SC current control loop. The bandwidth of the outer voltage loop is typically $10 \%$ of the inner current loops. It is very effective in preventing fast varying currents from flowing through the battery. The control scheme of the SC also includes a voltage loop to keep the voltage of the SC within a desired range, typically $50 \%$ to $100 \%$ of its rated value. By setting the reference voltage at $79 \%$ of the rated value, the SC has a state-of-charge with equal energy capacity to supply and absorb power before reaching the limit voltage values. Its bandwidth is typically $10 \%$ of that of the voltage (droop) loop of the HESS. Splitting the total current $\left(I_{L_{-} S t o r a g e}\right)$ supplied by HESS into average components, that is the battery reference current, and the transient power component, that is the SC reference current, helps in improving the operation of the battery but it does not improve the DC bus voltage dynamics. Moreover, a common voltage loop is used to generate the total current $\left(I_{L_{-} S t o r a g e}\right)$ to be supplied by the HESS, which requires 
a communication means between the battery and the SC converters. This is not appropriate to be used in nanogrids with DERs operating in a decentralized way with droop control and DC bus signaling.

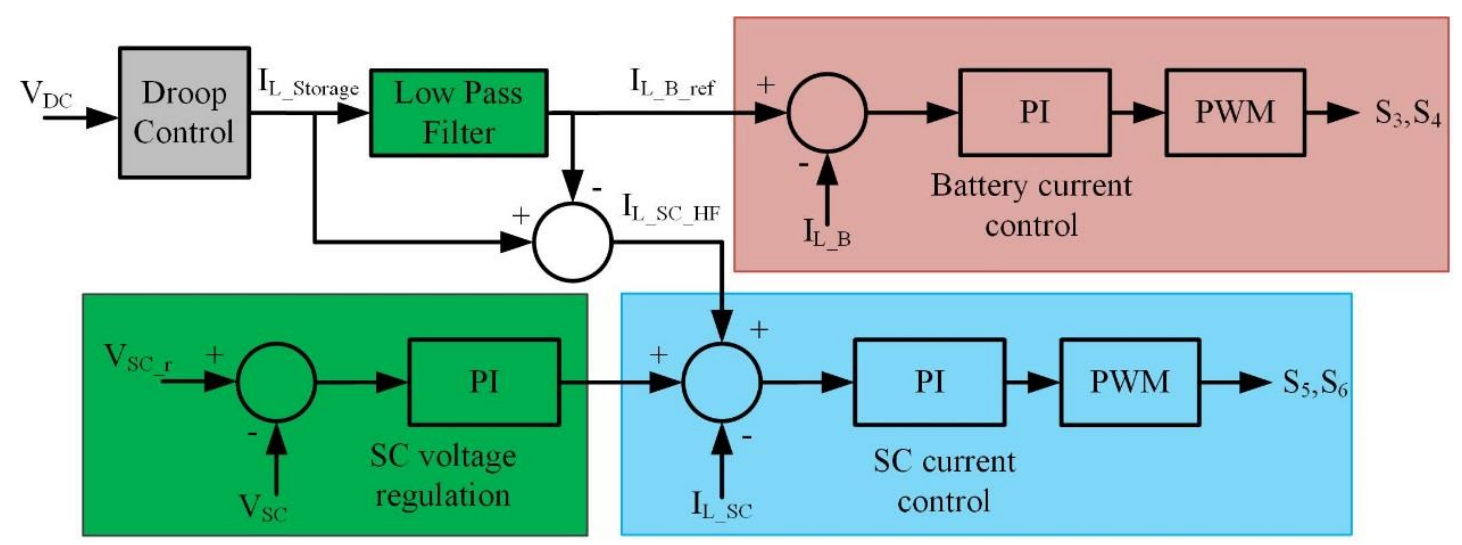

Figure 3. Schematic diagram of the conventional control scheme of the co-located battery-supercapacitors (SCs) hybrid energy storage systems (HESSs).

In the proposed approach shown in Figure 4, the SC interface is controlled independently from the battery one, which will allow it to provide additional services to the DC nanogrid. This is achieved by selecting a droop factor for the SC interface much smaller than the battery's, which is equivalent to a higher gain for its outer DC bus voltage loop. As a result, it will provide a much larger current reference for a given DC bus voltage variation, what should improve the dynamic voltage regulation. Recall that the SC is inherently capable of providing/absorbing high bursts of power. However, due to its low energy density, the duration of the power bursts should be limited, what can be done by introducing a HPF with suitable time constant in the input of its inner current loop. On the other hand, there is no need for a LPF in the input of the inner current loop of the battery interface, assuming that the SC interface will prevent sharp variations in the DC bus voltage and consequently sharp variations in the reference current of the battery interface.

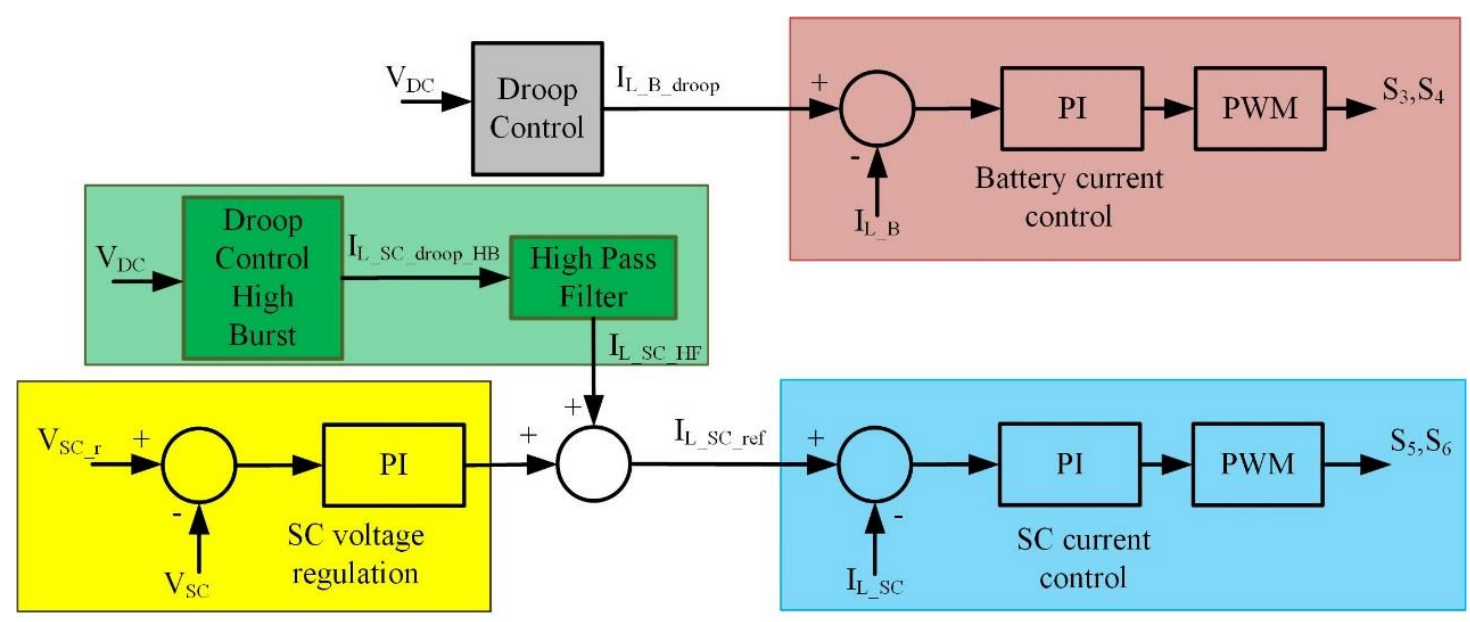

Figure 4. Proposed battery-SC control diagram.

The proposed control scheme has two parameters for design: the droop factor $\left(R_{d S C 1}\right)$ and the time constant $\left(\tau_{F}\right)$ of the HPF. The first has a major impact on the peak value of the injected current, due to a sudden DC bus voltage variation, while both affect the duration of the high burst of power. Based on Equation (2), the droop factor $R_{d S C 1}$ defines how much current is injected/absorbed into/from the DC grid as a function of a voltage difference $\left(V_{N L}\right.$ and $\left.V_{D C}\right)$. If the SC unit is to provide meaningful 
current bursts for assisting with dynamic voltage regulation, its droop factor should be much smaller (approximately $2 \%$ to 10\%) than that of the battery converter. On the other hand, it is desirable that this current burst lasts just long enough to mitigate the DC bus voltage variations so as not to drain/supply much energy from/to the SC unit. This can be accomplished with the appropriate choice of the time constant $\left(\tau_{F}\right)$ of the HPF.

In order to select these parameters, a dynamic model of the system, including the small-signal model of the SC interface (class C DC-DC converter) as shown in Figure 5, is considered. Assuming that the solar converter operates in the MPPT mode, it is modeled by a virtual constant current source. The battery converter operates with droop control and can be represented by a Thévenin model with a voltage source equal to the threshold voltage and a resistor equal to the droop factor $\left(R_{d B}\right)$ of the battery converter [17]. DC bus voltage variations shall occur mostly due to load variations.

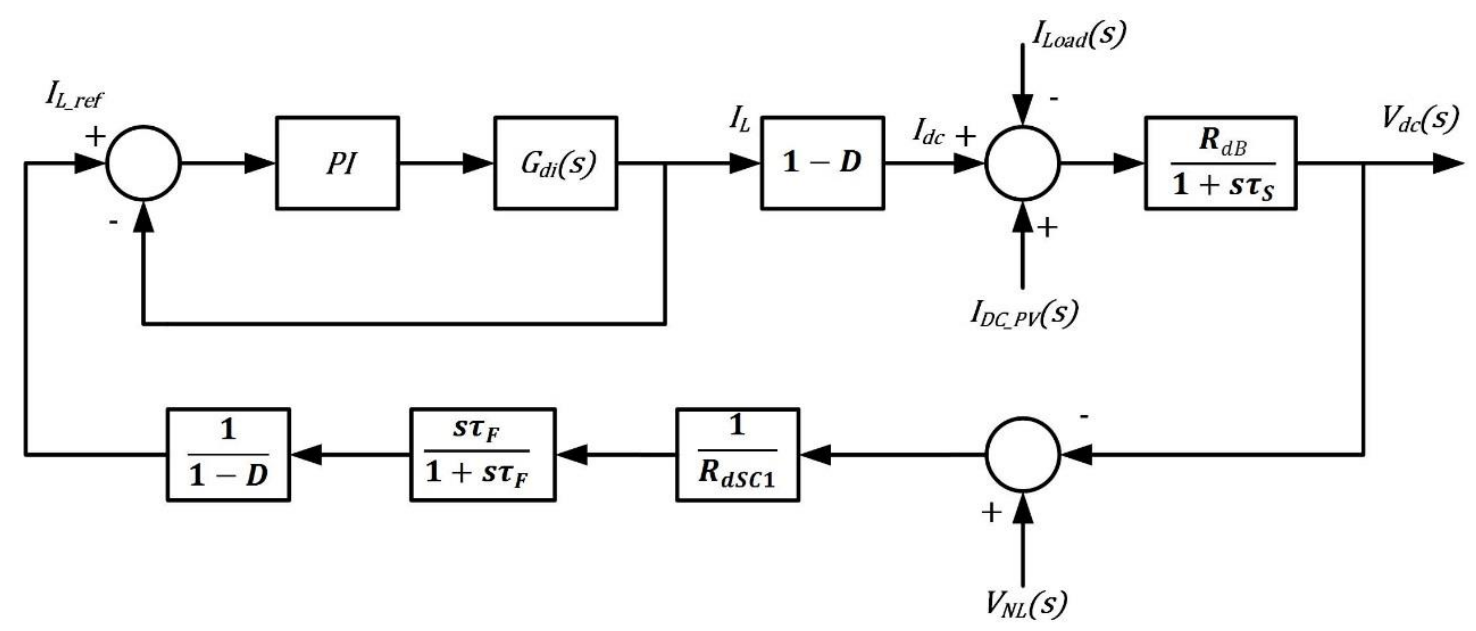

Figure 5. Small-signal model for the analysis of the proposed SC control scheme.

Figure 5 shows the small-signal model of the system, based on $[6,18]$. It includes the inner boost inductor current $\left(I_{L}\right)$ control loop with a PI-type controller and the duty-cycle to inductor current transfer function $(G d i(s))$ of the converter. The outer (droop) voltage control loop is based on a droop factor $\left(R_{d S C 1}\right)$, that concerns the DC bus voltage $\left(V_{d c}\right)$ and the reference injected current $\left(I_{d c}\right)$. The slow $\mathrm{SC}$ voltage control loop is neglected in this analysis. A first-order high-pass filter (HPF) with time constant $\tau_{F}$ is used in this work, where

$$
\tau_{F}=\frac{1}{2 \pi f_{c}} .
$$

The power converter is assumed to be ideal and a gain factor $(1-D)$ is employed to refer quantities from the DC bus to the SC side of the power converter, and vice-versa. A time constant for the DC nanogrid side $\left(\tau_{S}\right)$ is defined from the droop factor of the battery converter $\left(R_{d B}\right)$, which is much lower than the equivalent load resistance $\left(R_{L}\right)$, and the output capacitance of the $S C$ interface $\left(C_{D C 3}\right)$. Thus,

$$
\tau_{S}=C_{D C 3} R_{d B}
$$

Since the outer voltage (droop) loop has a much lower bandwidth than the inner current loop, the latter, which presents a zero error in steady-state due to the PI controller, can be simplified to a unity gain. Then, one can assume that there will be no variations in $V_{N L \_S C}$ and that load and PV current variations can be combined in a single element $\left(I_{\Delta}\right)$. Finally, the block diagram describing the dynamics of the system can be further simplified as shown in Figure 6. 


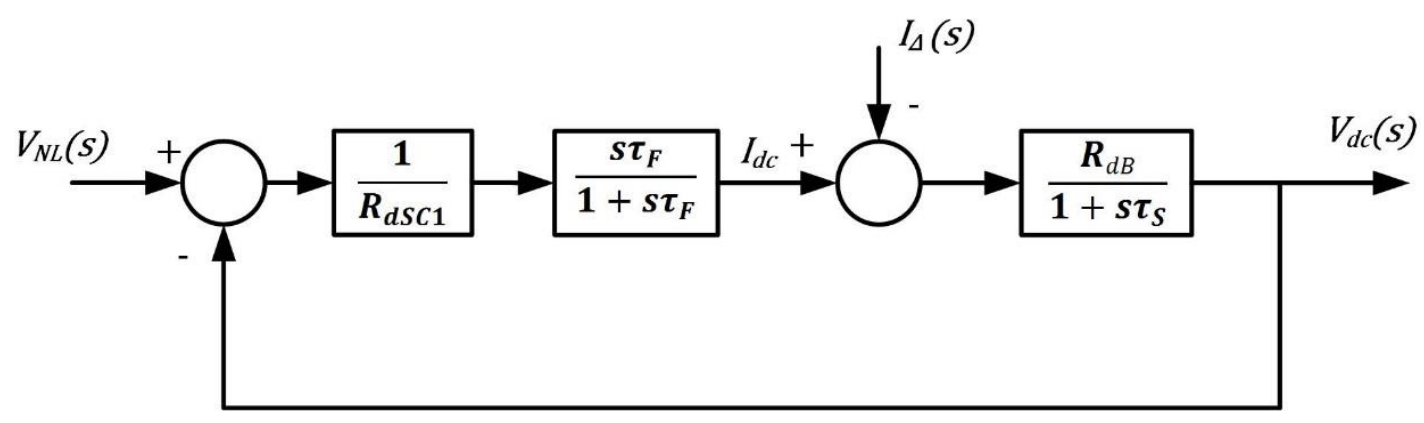

Figure 6. Simplified small-signal model for the analysis of the proposed SC control scheme.

The system's transfer function $\left(G_{T}\right)$ is given by:

$$
G_{T}(s)=\frac{V_{d c}(s)}{I_{\Delta}(s)}=\frac{G(s)}{1+k G(s) H(s)}
$$

where

$$
G(s) H(s)=\frac{s \tau_{F} R_{d B}}{\left(1+s \tau_{F}\right)\left(1+s \tau_{S}\right)}
$$

and

$$
k=\frac{1}{R_{d S C 1}} .
$$

The characteristic equation of the system is:

$$
\Delta=s^{2}+s \frac{\left(\tau_{F} R_{d B}+\tau_{S} R_{d S C 1}+\tau_{F} R_{d S C 1}\right)}{\left(\tau_{F} \tau_{S} R_{d S C 1}\right)}+\frac{1}{\left(\tau_{F} \tau_{S}\right)} .
$$

It can be represented in terms of the damping ratio $(\zeta)$ and the natural frequency $\left(\omega_{n}\right)$ as:

$$
\Delta=s^{2}+2 \zeta \omega_{n} s+\omega_{n}^{2}
$$

where

$$
\omega_{n}=\frac{1}{\sqrt{\tau_{F} \tau_{S}}}
$$

and

$$
\zeta=\frac{1}{2} \frac{\left(\tau_{F}\left(R_{d B}+R_{d S C 1}\right)+\tau_{S} R_{d S C 1}\right)}{R_{d S C 1} \sqrt{\tau_{F} \tau_{S}}} .
$$

The impact of the value of the droop factor $\left(R_{d S C 1}\right)$ and time constant $\left(\tau_{F}\right)$ of the HPF on the dynamic response of the system can be observed by means of the root locus method. The latter determines the location of one of the open loop roots while the former affects the position of the closed loop roots. Figure 7 shows the root locus of the system for $R_{d B}=0.289 \Omega$ and $C_{D C 3}=1500 \mu \mathrm{F}$. For the analysis, the cut-off frequency of the HPF is taken as $50 \mathrm{~Hz}$. Since transfer function $G$, (6), has two negative real poles and one zero at the origin, the system is stable for any gain $k$. As $k$ increases $\left(R_{d S C 1}\right.$ decreases), one closed loop real root moves towards the infinity and the other, dominant, towards the vertical axis. For a high enough $k$, one can neglect the non-dominant root. 


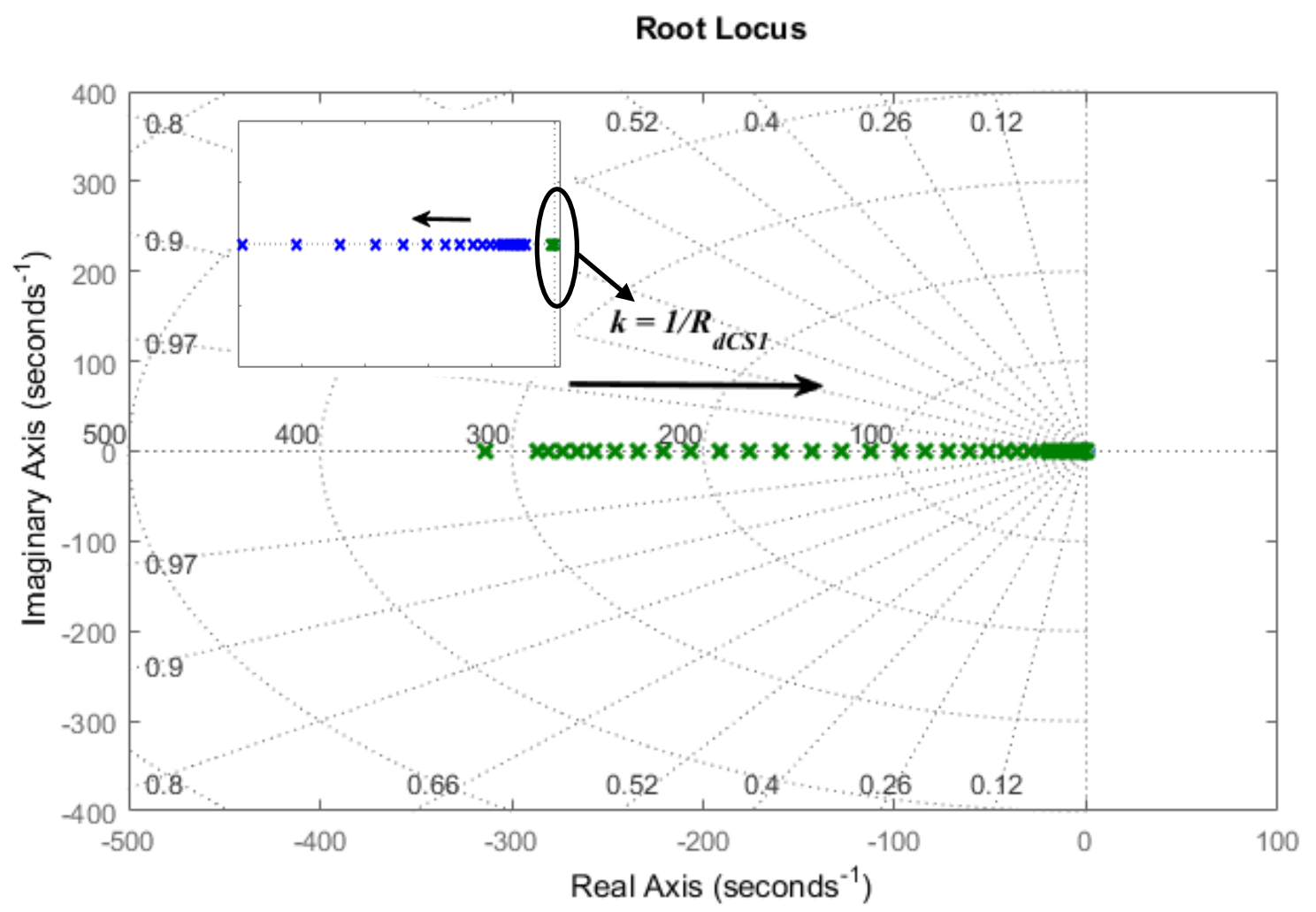

Figure 7. Root locus for varying the value of $R_{d S C 1}$ with $\tau_{F}=3.18 \mathrm{~ms}$.

As mentioned before, small values for $R_{d S C 1}$, from $2 \%$ to $10 \%$ of $R_{d B}$, should lead to a large enough burst of current to assist with dynamic DC bus voltage regulation what should also prevent the battery from supplying fast changing currents. Once the value of $R_{d S C 1}$ is selected, one can compute $\tau_{F}$ based on the desired duration of the high burst of power $\left(T_{S}\right)$. For a system $\left(G_{T}\right)$ with a dominant real root, one can say that $T_{S}=3 \tau$, where $\tau$ is the time constant of the dominant root. For a system with a negligible root, $\zeta \gg 1$ and

$$
\tau=\frac{1}{\left(\zeta-\sqrt{\zeta^{2}-1}\right) \omega_{n}},
$$

Then, for a specific desired time constant $\tau$, one can solve (12) with $\omega_{n}$ from (10) and $\zeta$ from (11) to find $\tau_{F}$. A closed form equation for $\tau_{F}$ is not straightforward. Alternatively, one can obtain the value of $\tau_{F}$ from a plot. Figure 8 shows the value of $1 / \tau$ as a function of $\tau_{F}$ for different values of $R_{d S C 1} / R_{d B}$ and for a system with $C_{D C 3}=1500 \mu \mathrm{F}$. As an example of usage of this approach, for $R_{d S C 1}=0.05 R_{d B}$, a HPF with $\tau_{F}=3.7 \mathrm{~ms}$ gives the settling time $T_{S}=0.22 \mathrm{~s}$. For $R_{d S C 1}=0.1 R_{d B}$, and the same HPF $\left(\tau_{F}=3.7 \mathrm{~ms}\right)$, the settling time becomes $T_{S}=0.12 \mathrm{~s}$. Alternatively, the original settling time $(0.22 \mathrm{~s})$ can be achieved with $R_{d S C 1}=0.1 R_{d B}$ and a HPF with a time constant of $\tau_{F}=6.9 \mathrm{~ms}$. It should be noted that as one decreases $R_{d S C 1}$, to have a higher burst of current and a smoother DC bus voltage variation following a sudden power unbalance in the DC nanogrid, a smaller time constant $\left(\tau_{F}\right)$ of $\mathrm{HPF}$ is needed for a given settling time. In addition, Figure 8 also shows the impact of $\tau_{F}$ on the damping ratio $\zeta$ and the natural frequency $\omega_{n}$. 

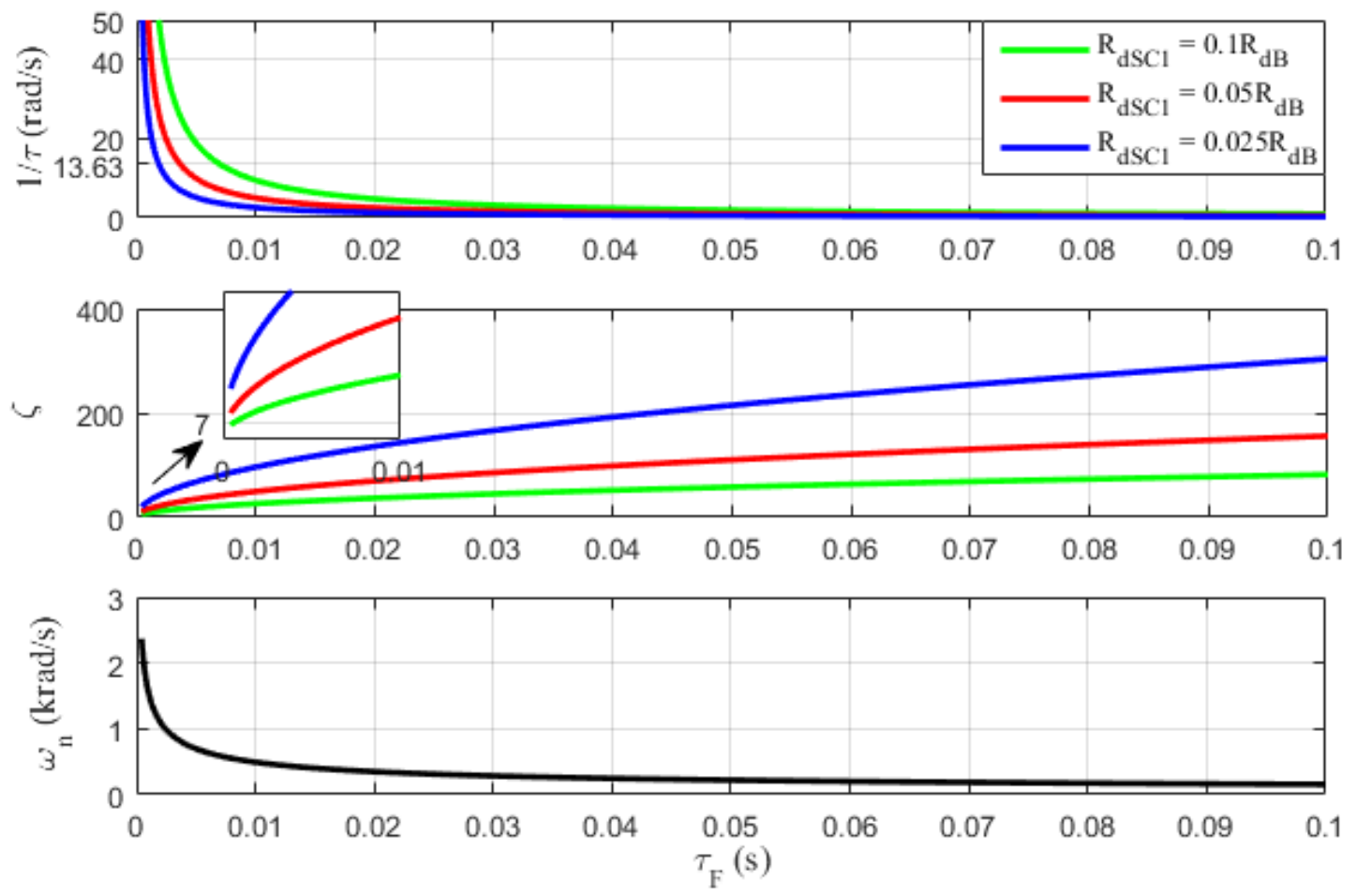

Figure 8. The relationship between $1 / \tau$ and $\tau_{F}$ for different droop factors of the SC unit $\left(R_{d S C 1}\right)$.

\section{Case Study}

As a case study in this paper, a 48 V DC nanogrid consisting of a PV-based RES, a battery unit, a SC unit and a variable load is considered. The PV panel provides a maximum power of $213 \mathrm{~W}$ with $7.35 \mathrm{~A}$ and $29 \mathrm{~V}$ at rated solar irradiance. Due to converter losses, it is considered that the maximum (rated) injected power by the PV unit is $200 \mathrm{~W}$. In order to comply with the voltage levels presented in Section 2, the DC bus voltage should vary between $49.2 \mathrm{~V}$ and $45.6 \mathrm{~V}$ in the MPPT region, where the solar converter would inject $4.1 \mathrm{~A}$ and $4.4 \mathrm{~A}$, respectively.

In the performance investigation to be conducted in the following Sections, the conventional control scheme for the HESS will be compared to the proposed one, which can also be used for non-co-located battery and SC units. The droop factor of the HESS $\left(R_{d_{-} S T}\right)$ is $0.289 \Omega$ and the cut-off frequency of the LPF for the frequency split is $43.5 \mathrm{~Hz}$. The HESS' threshold voltage $\left(V_{N L_{-} S T}\right)$ is $48 \mathrm{~V}$ and the current limit value is the maximum current supplied by the PV converter $\left(I_{S T-c}=I_{P V-c}=4.4 \mathrm{~A}\right)$. Concerning the proposed scheme, the threshold voltages of the battery and SC converters, $V_{N L_{-} B}$ and $V_{N L \_S C}$, are equal to $V_{N L_{-} S T}$ and their rated currents are equal to the maximum current supplied by the PV converter $\left(I_{B-c}=I_{S C-c}=I_{P V-c}=4.4 \mathrm{~A}\right)$. The droop factor of the battery converter is $R_{d B}=R_{d \_S T}$ $=0.289 \Omega$, while that of the SC, which as discussed in Section 3 should be 20 times lower than the battery's, is $R_{d S C 1}=0.0145 \Omega$. The cut-off frequency of the HPF for the proposed SC control loop was calculated as described in Section 3 for $T_{S}=0.22 \mathrm{~s}$ and is equal to $43.5 \mathrm{~Hz}$.

Regarding the power electronic interfaces, the DC-DC converters of all elements are very similar, with the exception of the unidirectional feature of the RES. They are realized with a single three-phase DC-AC converter as shown in Figure 9, for simulation studies and in the experimental set-up. The capacitor of the DC bus (nanogrid) voltage is equal to $1500 \mu \mathrm{F}$. LC filters (100 $\mu \mathrm{H}$ and $470 \mu \mathrm{F})$ are connected between the mid-points of the three-phase inverter legs and the storage and the source elements, to create the classical class C DC-DC converters. The converters operate with pulse-width modulation (PWM) and a switching frequency of $20 \mathrm{kHz}$. 


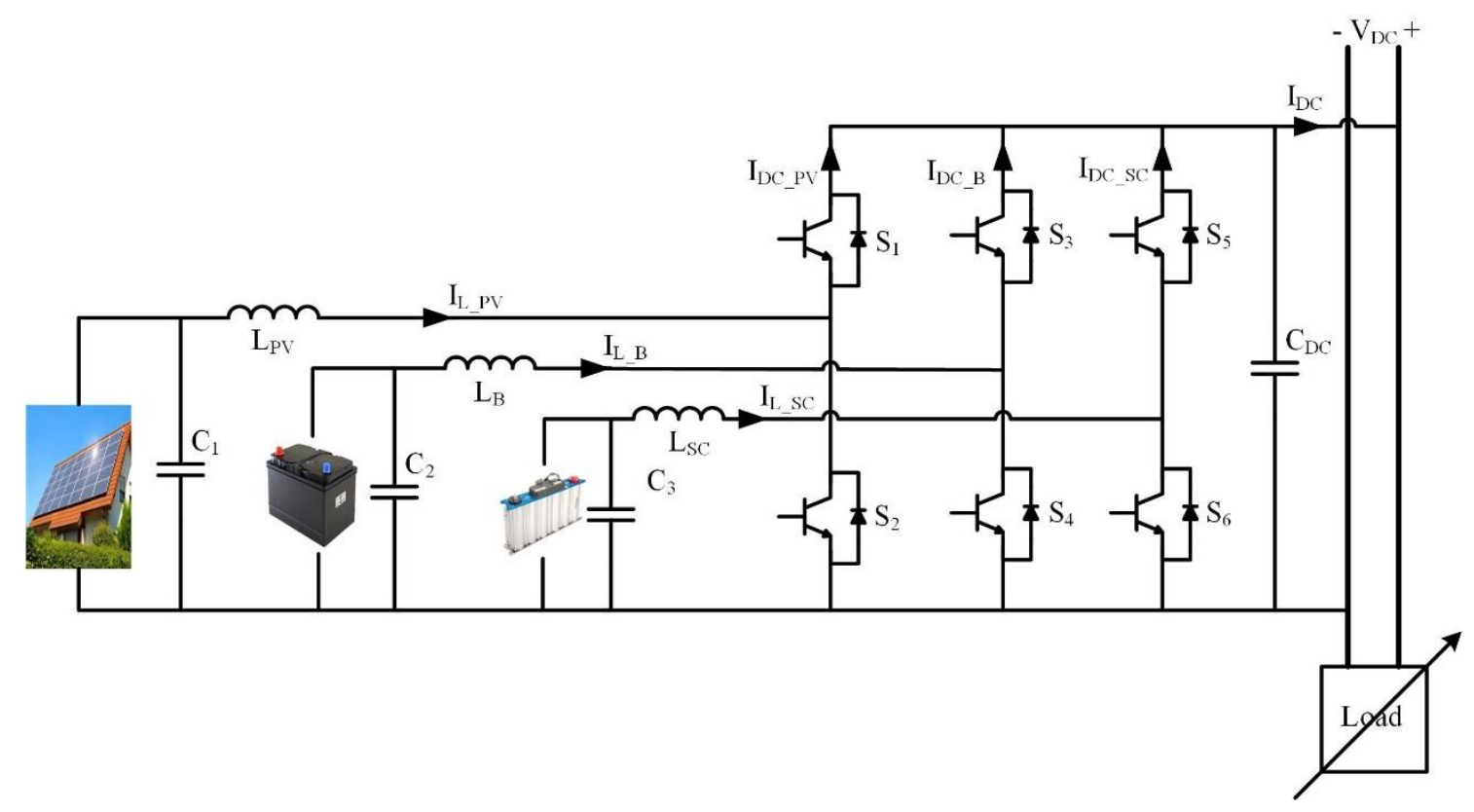

Figure 9. DC nanogrid power electronics interfaces.

The same current control loop can be used for all DERs. A PI type-III controller was designed for the same equivalent plant with a transfer function shown in $(13)[6,18]$. They were designed for a crossover frequency of $f_{x}=2 \mathrm{kHz}$ ( $10 \%$ of the switching frequency) and phase margin of $P M=80^{\circ}$. The following plant parameters were assumed: $V_{D C}=48 \mathrm{~V}, I_{D C}=4.44 \mathrm{~A}, R=10.8 \Omega, L=100 \mu \mathrm{H}$, $C=1500 \mu \mathrm{F}$, and $D=0.46$ for $V_{P V}=V_{B a t}=V_{S C}=29 \mathrm{~V}$. $R$ was selected as the maximum load that could be supplied by the RES alone. At the end, the PI controller parameters are computed as $K_{P I}=0.0114$, $\tau=171 \mu \mathrm{s}$ and $T_{P}=37 \mu \mathrm{s}$.

$$
G_{d i}(s)=\frac{\widetilde{i}_{L}(s)}{\widetilde{d}(s)}=\frac{C V_{D C} s+2 I_{D C}}{L C s^{2}+\frac{L}{R} s+(1-D)^{2}}
$$

\section{Simulation Results}

MATLAB/Simulink is used for simulation studies. The objective is to investigate the potential benefits of an independently controlled SC unit in the dynamic regulation of the DC nanogrid voltage. Ideally, this should not affect the ability of the SC unit to mitigate the high frequency and fast changing currents in the battery. In order to test this feature, the solar converter operates in MPPT while the power demanded from the DC nanogrid varies between no-load and full-load. From $t=0 \mathrm{~s}$ to $0.05 \mathrm{~s}$, there is no power demanded from the DC nanogrid, and the storage unit(s) absorbs all the power provided by the RES, around $200 \mathrm{~W}$. Then a full-load impedance of $5.2 \Omega$ is connected to the DC nanogrid to be supplied by both the RES and storage unit(s), both at full power. This operating condition remains until $0.05 \mathrm{~s}$ when the load is removed. This corresponds to the largest normal disturbance to be faced by the DC nanogrid and will be used to compare the performance of the proposed control scheme with the conventional one with a HESS. The parameters of the system are as stated in previous Sections. (The battery and SC were represented by ideal DC voltage sources of $24 \mathrm{~V}$ and $28.4 \mathrm{~V}$, respectively.)

Figure 10 shows the results of the key system waveforms for the conventional scheme. Initially at no-load, the DC nanogrid voltage (top screen) is about $49.25 \mathrm{~V}$. The solar converter operates in the MPPT mode with a boost inductor current (average) of around $7.35 \mathrm{~A}$, bottom screen. The average current absorbed (negative sign) by the battery is $8.4 \mathrm{~A}$ while that of the SC is zero, as expected. Following the load step, the SC current increases very fast reaching a peak value of $10 \mathrm{~A}$, while the 
battery's increases more slowly, as desired, until it supplies all the HESS current. The DC bus voltage reaches the steady-state value of $46.75 \mathrm{~V}$ in $17 \mathrm{~ms}$. A similar behavior, in terms of current magnitudes and settling times, can be observed when the load is removed at $t=0.3 \mathrm{~s}$ and the HESS has to, again, absorb rated power.
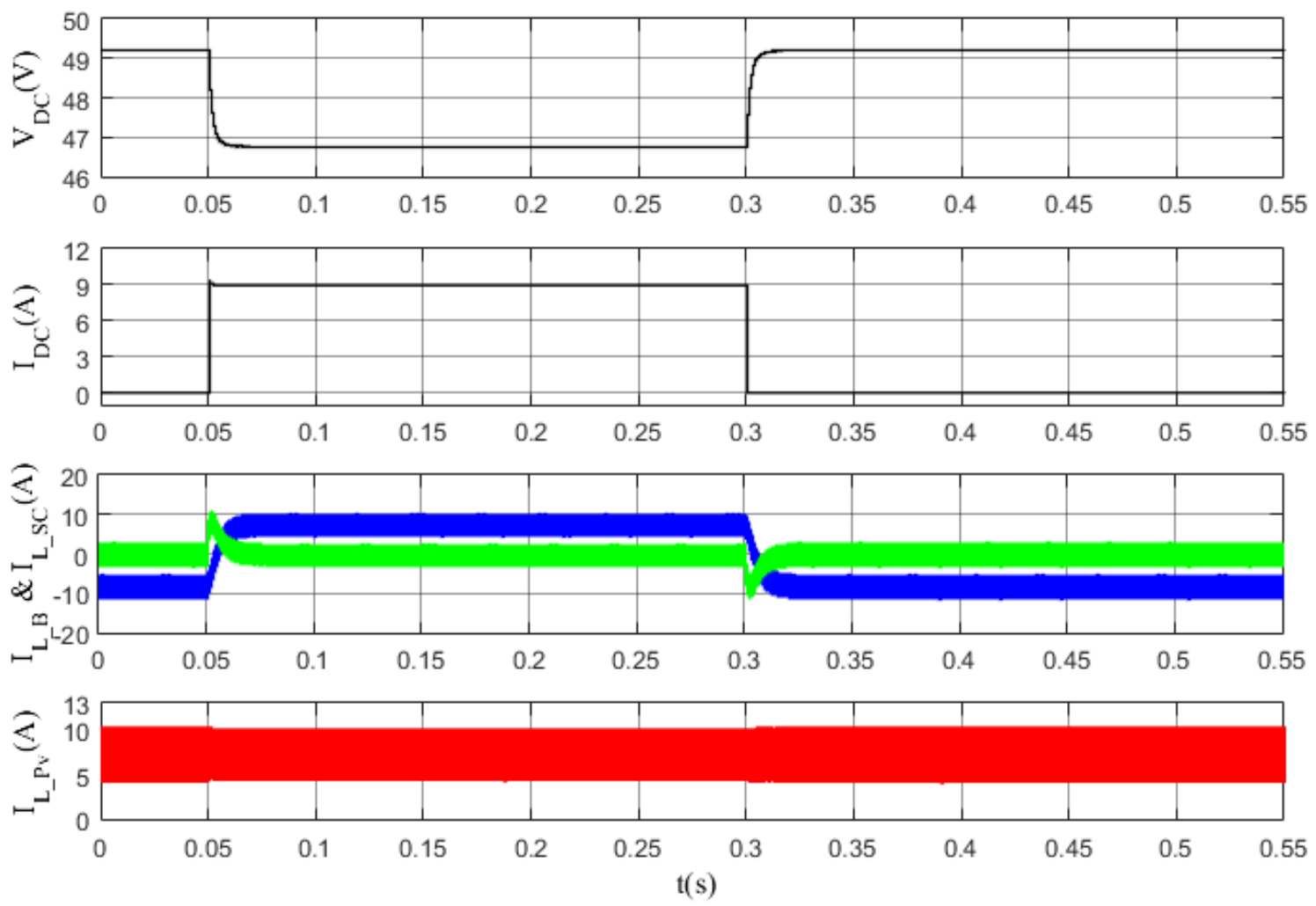

Figure 10. Simulation results for the conventional approach when the load changed from no-load to $5.2 \Omega$ (full nanogrid load) and back to no-load.

Figure 11 shows the performance of the system, for the same load transients, with the proposed control scheme. The values of the waveforms in the steady-state for the no-load condition are virtually the same as for the conventional HESS control scheme. Following the full-load step variation, one can see that the DC bus voltage decreases much more slowly than with the conventional HESS control approach. This is due to the way the SC converter is controlled, injecting a higher current and for a longer time to slow down the reduction of the DC bus voltage. At the same time, as expected, it slowed down the increase of the battery current. This was done indirectly, via the DC bus voltage, without any signals exchanged between the control loops of the battery and SC converters. Just before $t=0.3 \mathrm{~s}$, the values of the waveforms obtained with the proposed scheme are very similar to those obtained with the conventional HESS scheme. Then, following a step load rejection, to no-load, the proposed scheme provides a similar improvement in the DC bus voltage variation and in the battery current variation. It is worth mentioning that besides using the proposed control scheme, one should also make sure that the SC is large enough to provide/absorb the required compensating energy without significant changes in its voltage level and that the boost inductor of the SC converter will not saturate with the increased current. Considering the relatively short action time of the proposed control scheme for the $\mathrm{SC}$ converter, it should not be necessary to increase the current ratings of the semiconductor switches. 

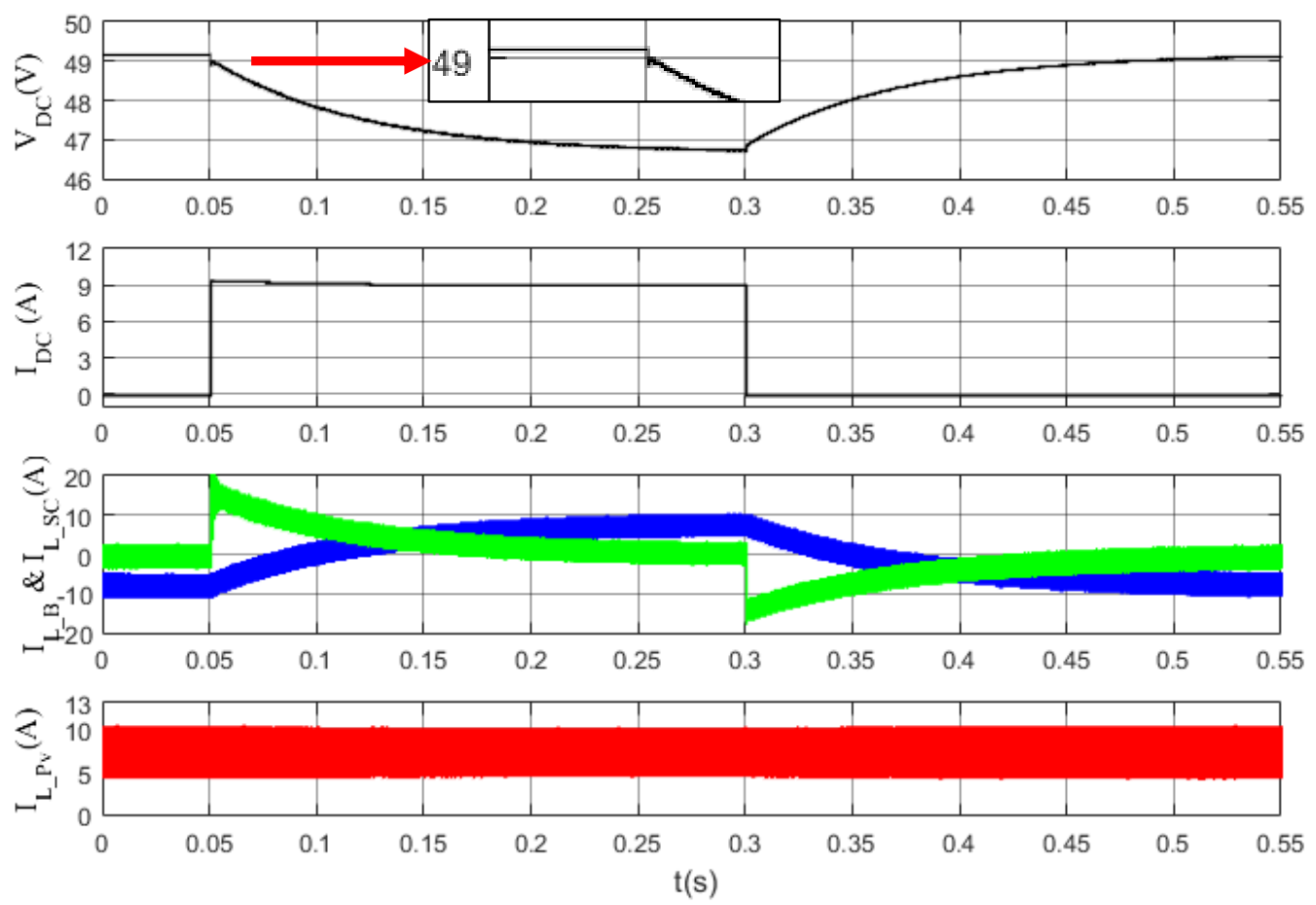

Figure 11. Simulation results for the proposed approach when the load is changed from no-load to $5.2 \Omega$ (full nanogrid load) and back to no-load.

\section{Experimental Results}

A DC nanogrid with a RES, two energy storage units and a variable load was assembled in the laboratory. An Agilent Solar Array Simulator (SAS) (E4350B) was used to emulate a solar array. It was programmed to provide a maximum power of $213 \mathrm{~W}$ with $7.35 \mathrm{~A}$ and $29 \mathrm{~V}$ at rated solar irradiance. Maxwell supercapacitor modules (BMOD0165 P048) of $165 \mathrm{~F}$ with a rated voltage of $48 \mathrm{~V}$ were employed for the energy storage units. One is used as a battery and the second is used as a SC. As in the simulation studies, the "battery voltage" was adjusted to $24 \mathrm{~V}$ and the SC's to 28.4 V. Regarding the power electronics interface, a Semikron "MiniSKiiP 8 Three-phase $1200 \mathrm{~V}$ Power board", with a MiniSKiiP 83 AC power module and a SKHI61 IGBT driver, was used in this study. The values of passive components, control parameters, and so on, used in the experimental set-up are those presented in Section 4. The control schemes are implemented with a dSPACE DS-1103 rapid prototyping system with a $20 \mu$ s time step. The dSPACE code was generated by Simulink C coder by means of Real-time interface (RTI), which converts the control diagram from MATLAB/Simulink into dSPACE code. This does not provide the fastest and the shortest code, but it is sufficient in experimental proof-of-concept tests. Eight parallel switchable $44 \Omega$ resistors were used for realizing the full DC nanogrid load impedance. A picture of the experimental set-up is shown in Figure 12.

Having demonstrated the improved performance of the proposed scheme over the conventional HESS control scheme by means of simulations, experimental results are provided to demonstrate the feasibility of the proposed control scheme. The focus of this Section is on the impact of different system parameters obtained using the proposed design approach.

The first case, which was also presented in the simulation studies, concerns a SC interface with a droop factor $R_{d S C 1}=0.0145,20$ times lower than the battery's for providing a peak current of 20 times that of the battery for a given DC bus voltage variation. It employs a HPF with a time constant $\tau_{F}=3.7 \mathrm{~ms}$, computed to give a settling time of $T_{s}=0.22 \mathrm{~s}$. The key waveforms of the system are shown in Figure 13 for a no-load to full-load (5.2 $\Omega$ ) variation and back to no-load. At no-load, the DC bus voltage is initially at $49.2 \mathrm{~V}$ and it decreases slowly to $46.8 \mathrm{~V}$ at full-load in the steady-state. (The screen shows $0.4 \mathrm{~V} /$ div.) The load current increases in a step-like manner from $0 \mathrm{~A}$ reaching $8.45 \mathrm{~A}$ in steady-state 
(1.3 A/div). The SC (inductor) current, initially at $0 \mathrm{~A}$, increases very fast following the load step, reaching a peak value of about $20 \mathrm{~A}$. Then, it decreases exponentially reaching $0 \mathrm{~A}$ after about $0.24 \mathrm{~s}$. The battery (inductor) current changes slowly from $-8 \mathrm{~A}$, when it absorbs the full PV power at no-load, to $8 \mathrm{~A}$, when it provides to the DC bus the same amount of power as the PV converter, at full-load (4 A/div). The PV (inductor) current remains virtually constant since it operates with MPPT with rated solar irradiance. The experimental waveforms match very well with the simulation ones.

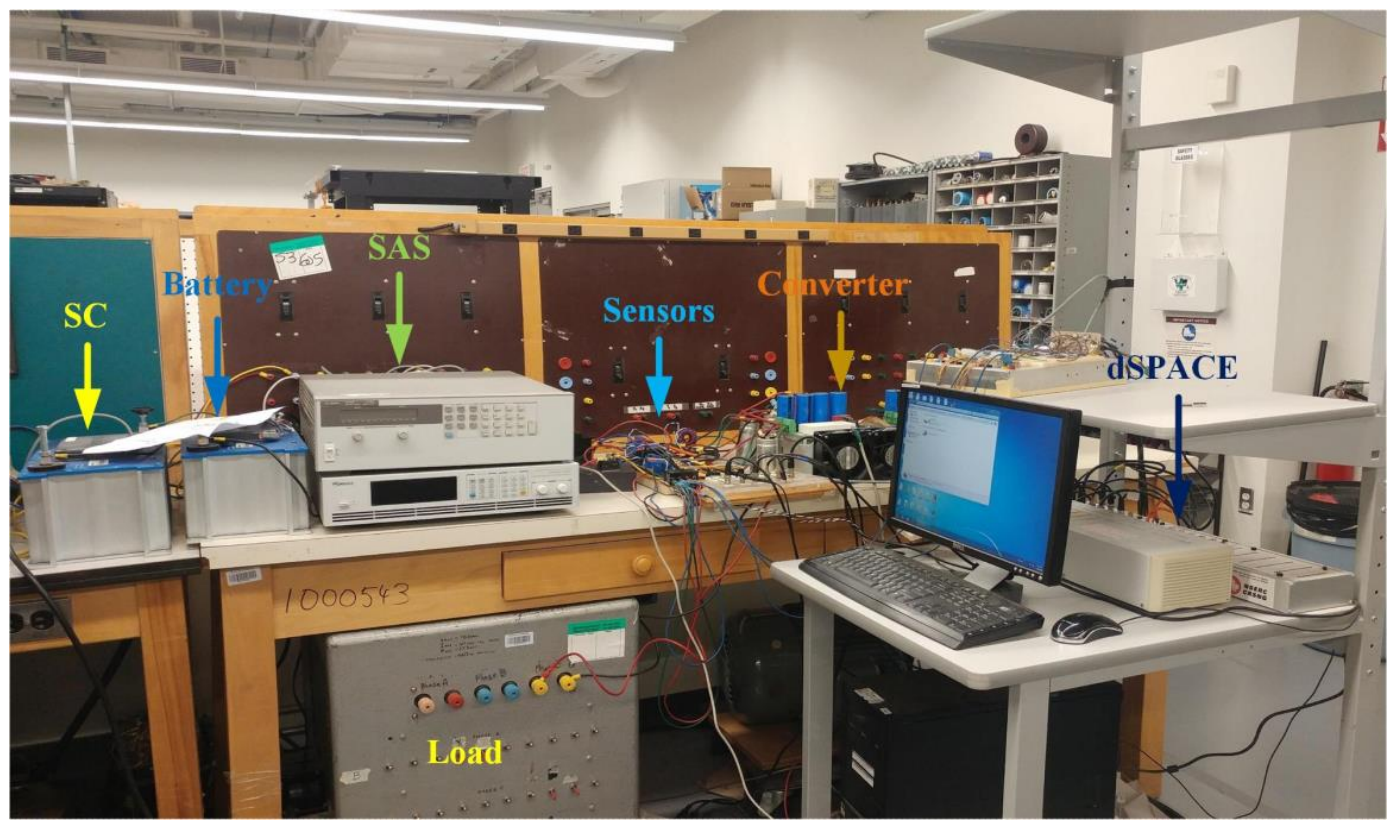

Figure 12. Picture of the experimental set-up assembled in the laboratory.

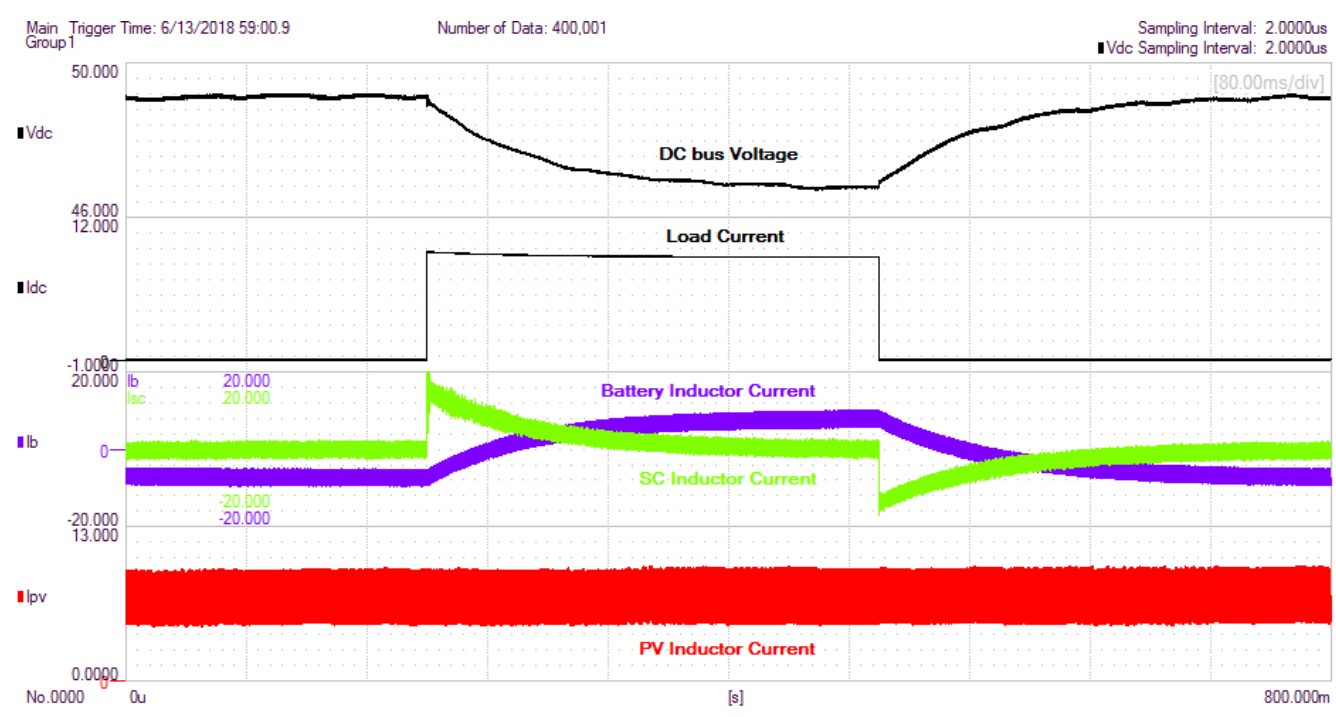

Figure 13. Experimental result for the proposed control scheme with $R_{d S C 1}=0.05 R_{d B}$ and designed for $T_{s}=0.22 \mathrm{~s}$, as the load changed from no-load to full-load $(5.2 \Omega)$ and back to no-load.

In the second case, a larger droop factor $\left(R_{d S C 1}=0.0289 \Omega\right)$, which is $10 \%$ of the battery's, is used. Thus, the SC converter should provide a lower contribution during transient conditions. The time constant of the HPF is calculated for the same value $\left(T_{S}=0.22 \mathrm{~s}\right)$, resulting in $\tau_{F}=6.9 \mathrm{~ms}$. Figure 14 shows the transient response of the system, with the abovementioned parameters, for the no-load to 
full-load and back to no-load transitions. By comparing the results with the previous ones, one sees that the DC bus voltage presents a larger step decrease, due to a lower peak SC (inductor) current, but it reaches the same steady-state value at full-load with the same delay as before, because of the design specification (settling time) used in both cases. The battery (inductor) current increased a bit faster as a result of the lower DC bus voltage during the transient condition. The PV (inductor) current remains virtually the same, identical to the previous case.

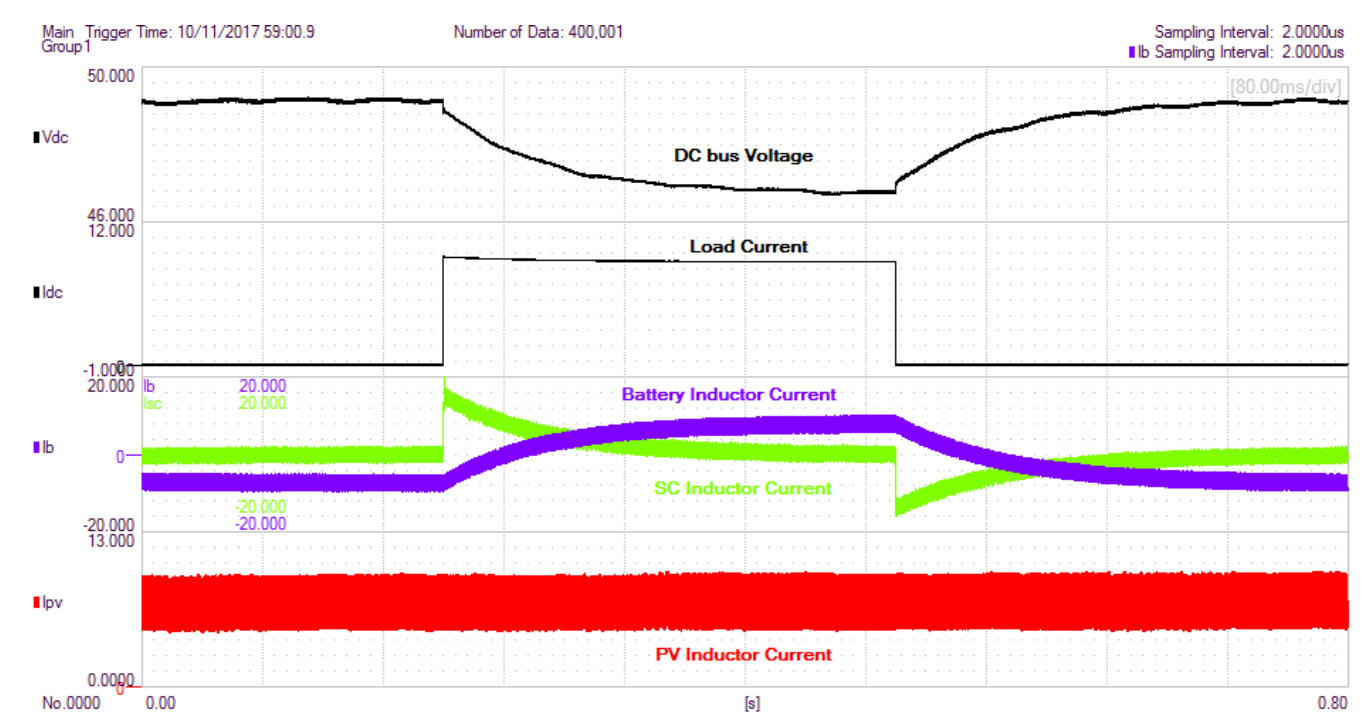

Figure 14. Experimental result for the proposed control scheme with $R_{d S C 1}=0.1 R_{d B}$ and designed for $T_{s}=0.22 \mathrm{~s}$, as the load changed from no-load to full-load (5.2 $\Omega$ ) and back to no-load.

The last case concerns a SC converter with a large droop factor $\left(R_{d S C 1}=0.0289 \Omega=0.1 R_{d B}\right)$, and with a HPF designed for a settling time $\left(T_{S}=0.12 \mathrm{~s}\right)$ resulting in $\tau_{F}=3.7 \mathrm{~ms}$. In such a case, the SC converter should present the lowest value, in terms of current magnitude, and a shorter contribution during the transient conditions of the three cases tested experimentally. As observed in Figure 15, its impact on the dynamic DC bus voltage regulation and battery (inductor) current waveform is obviously lower. However, this can be achieved with lower energy required from the SC and potentially a smaller (capacitance) SC, for the same SC voltage variation.

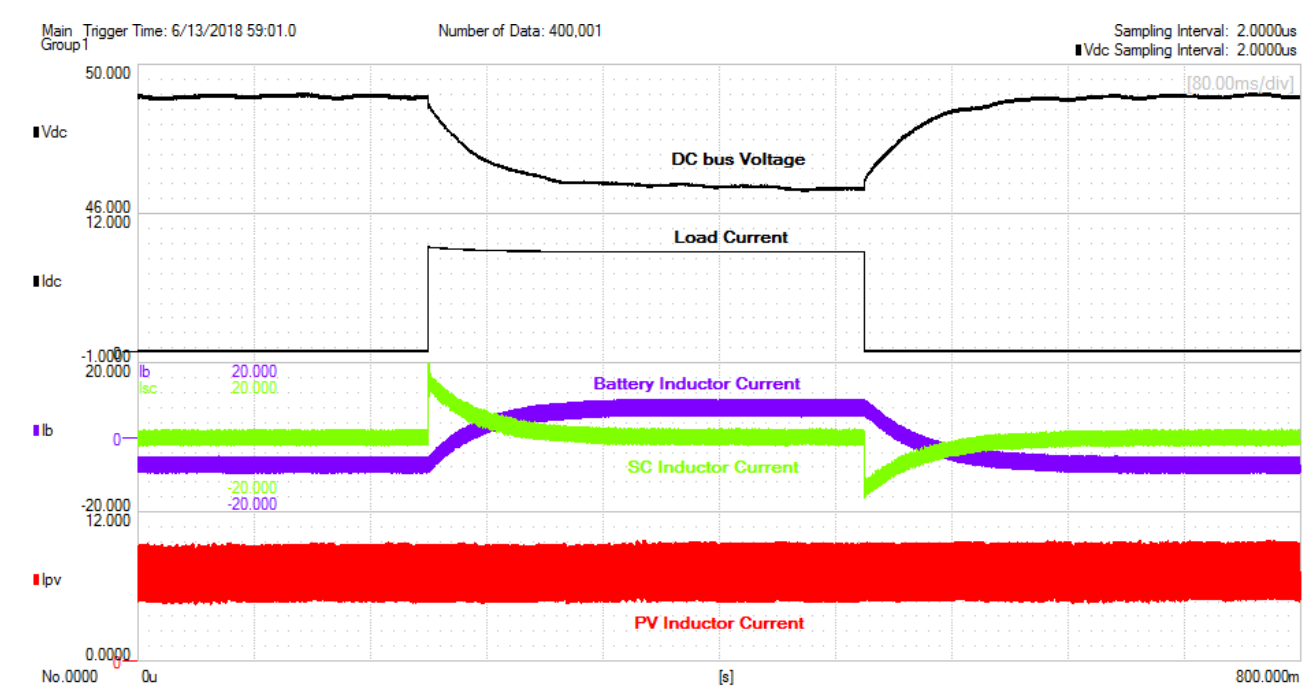

Figure 15. Experimental result for the proposed control scheme with $R_{d S C 1}=0.1 R_{d B}$ and designed for $T_{S}=0.12 \mathrm{~s}$, as the load changed from no-load to full-load (5.2 $\Omega$ ) and back to no-load. 


\section{Conclusions}

Hybrid energy storage systems (HESSs) with battery and supercapacitors (SCs) can play an important role in autonomous DC nanogrids with stochastic renewable energy sources (RESs) and highly variable loads. The battery and SCs are usually co-located and, in droop-controlled DC grids, controlled with a single V-I curve. The appropriate current contributions of the battery (slow components) and SC (fast components) are obtained with low-pass or high-pass filters (HPFs). Since the droop slope of the HESS is determined based on steady-state conditions, it is relatively large, preventing the HESS from providing high and fast varying currents for effective dynamic DC bus voltage regulation. This paper proposed the independent control of battery and SC units, which can be co-located or not. The battery control scheme remains focused on steady-state conditions, while one assigns a small droop slope to the SC unit for it to respond strongly to minor DC bus voltage variations. In order to prevent the SC from supplying/absorbing large amounts of energy, a HPF is included in its control loop. A design approach was presented and the performance of the proposed scheme was validated by means of simulation and experimental results. It allows the SC unit to improve the dynamic voltage regulation of the DC nanogrid while, indirectly, mitigating the potentially high and fast current variations in the battery unit.

Author Contributions: Conceptualization, A.M.A.M. and L.A.C.L.; Methodology, A.M.A.M. and L.A.C.L.; Validation, A.M.A.M.; Investigation, A.M.A.M. and L.A.C.L.; Writing-Original Draft Preparation, A.M.A.M.; Writing-Review \& Editing, A.M.A.M. and L.A.C.L.; Supervision, L.A.C.L.

Funding: This research was funded by the Natural Sciences and Engineering Research Council (NSERC) of Canada grant number N00863.

Acknowledgments: The authors appreciate the support provided by The University of Jordan, through the College of Engineering, and of the Natural Sciences and Engineering Research Council (NSERC) of Canada.

Conflicts of Interest: The authors declare no conflict of interest.

\section{References}

1. Alepuz, S.; Busquets-Monge, S.; Bordonau, J.; Gago, J.; Gonzalez, D.; Balcells, J. Interfacing Renewable Energy Sources to the Utility Grid Using a Three-Level Inverter. IEEE Trans. Ind. Electron. 2006, 53, 1504-1511. [CrossRef]

2. Sartori, I.; Napolitano, A.; Voss, K. Net zero energy buildings: A consistent definition framework. Energy Build. 2012, 48, 220-232. [CrossRef]

3. Wei, Z.; Zhao, J.; Ji, D.; Tseng, K.J. A multi-timescale estimator for battery state of charge and capacity dual estimation based on an online identified model. Appl. Energy 2017, 204, 1264-1274. [CrossRef]

4. Wei, Z.; Meng, S.; Xiong, B.; Ji, D.; Tseng, K.J. Enhanced online model identification and state of charge estimation for lithium-ion battery with a FBCRLS based observer. Appl. Energy 2016, 181, 332-341. [CrossRef]

5. Manandhar, U.; Tummuru, N.R.; Kollimalla, S.K.; Ukil, A.; Beng, G.H.; Chaudhari, K. Validation of Faster Joint Control Strategy for Battery-and Supercapacitor-Based Energy Storage System. IEEE Trans. Ind. Electron. 2018, 65, 3286-3295. [CrossRef]

6. Kollimalla, S.K.; Mishra, M.K.; Narasamma, N.L. Design and Analysis of Novel Control Strategy for Battery and Supercapacitor Storage System. IEEE Trans. Sustain. Energy 2014, 5, 1137-1144. [CrossRef]

7. Pegueroles-Queralt, J.; Bianchi, F.D.; Gomis-Bellmunt, O. A Power Smoothing System Based on Supercapacitors for Renewable Distributed Generation. IEEE Trans. Ind. Electron. 2015, 62, 343-350. [CrossRef]

8. Abbey, C.; Li, W.; Joos, G. An Online Control Algorithm for Application of a Hybrid ESS to a Wind-Diesel System. IEEE Trans. Ind. Electron. 2010, 57, 3896-3904. [CrossRef]

9. Mendis, N.; Muttaqi, K.M.; Perera, S. Management of Battery-Supercapacitor Hybrid Energy Storage and Synchronous Condenser for Isolated Operation of PMSG Based Variable-Speed Wind Turbine Generating Systems. IEEE Tran. Smart Grid 2014, 5, 944-953. [CrossRef]

10. Hredzak, B.; Agelidis, V.G.; Jang, M. A Model Predictive Control System for a Hybrid Battery-Ultracapacitor Power Source. IEEE Trans. Power Electron. 2014, 29, 1469-1479. [CrossRef] 
11. Shen, J.; Khaligh, A. A Supervisory Energy Management Control Strategy in a Battery/Ultracapacitor Hybrid Energy Storage System. IEEE Trans. Transp. Electrif. 2015, 1, 223-231. [CrossRef]

12. Tummuru, N.R.; Mishra, M.K.; Srinivas, S. Dynamic Energy Management of Renewable Grid Integrated Hybrid Energy Storage System. IEEE Trans. Ind. Electron. 2015, 62, 7728-7737. [CrossRef]

13. Chedid, R.; Rahman, S. Unit sizing and control of hybrid wind-solar power systems. IEEE Trans. Energy Convers. 1997, 12, 79-85. [CrossRef]

14. Dalbon, W.; Roscia, M.; Zaninelli, D. Hybrid photovoltaic system control for enhancing sustainable energy. In Proceedings of the IEEE Power Engineering Society Summer Meeting, Chicago, IL, USA, 21-25 July 2002.

15. Kakigano, H.; Nishino, A.; Ise, T. Distribution voltage control for DC microgrid with fuzzy control and gain-scheduling control. In Proceedings of the 8th International Conference on Power Electronics-ECCE Asia, Jeju, Korea, 30 May-3 June 2011; Volume 5, pp. 256-263.

16. Gu, Y.; Li, W.; He, X. Frequency-Coordinating Virtual Impedance for Autonomous Power Management of DC Microgrid. IEEE Trans. Pow. Electron. 2015, 30, 2328-2337. [CrossRef]

17. Rodriguez, M.; Stahl, G.; Corradini, L. Smart DC power management system based on software-configurable power modules. IEEE Trans. Pow. Electron. 2013, 28, 1571-1586. [CrossRef]

18. Kolluri, S.; Narasamma, N.L. Analysis, modeling, design and implementation of average current mode control for interleaved boost converter. In Proceedings of the 2013 IEEE 10th International Conference on Power Electronics and Drive Systems (PEDS), Kitayushu, Japan, 22-25 April 2013.

(C) 2018 by the authors. Licensee MDPI, Basel, Switzerland. This article is an open access article distributed under the terms and conditions of the Creative Commons Attribution (CC BY) license (http://creativecommons.org/licenses/by/4.0/). 